\title{
Electrospun nanofibrous membrane for filtration of coconut neera
}

\author{
M. Maria Leena ${ }^{1} \cdot$ K. S. Yoha ${ }^{1} \cdot$ J. A. Moses ${ }^{1} \cdot$ C. Anandharamakrishnan ${ }^{1}$
}

Received: 30 December 2020 / Accepted: 20 March 2021 / Published online: 23 April 2021

(c) The Author(s), under exclusive licence to Springer Nature Switzerland AG 2021

\begin{abstract}
Coconut neera is a nutritious natural drink that is rich in amino acids, polyphenols, vitamins, and minerals. Nevertheless, the inherent presence of yeast activates natural fermentation. To prevent the fermentation process, it is necessary to reduce the yeast load in fresh neera, at the earliest possible. In this research, an electrospun polycaprolactone nanofibrous membrane was used for the removal of yeast from coconut neera. Randomly oriented non-woven nanofibers were fabricated using the electrospinning process. The process conditions were optimized at $15 \mathrm{kV}$ applied voltage, $8 \mathrm{~cm}$ distance between the spinneret needle and the collector plate, and $1.6 \mathrm{ml} / \mathrm{h}$ feed flow rate for the best nanofiber characteristics and high filtration efficiency. The optimized nanofibrous membrane for neera filtration had an average fiber diameter of $942 \mathrm{~nm}$, average porosity of $73.26 \%$, and a mean thickness of $150 \mu \mathrm{m}$. Results confirmed that the porosity of the membrane had a significant effect on the flow rate of permeate. The biochemical characteristics of neera filtrate were investigated. In comparison with fresh neera, the filtered counterpart had significant changes in titratable acidity, $\mathrm{pH}$, and color. While no significant changes were observed in total soluble solids content, slight reductions were noted in the total polyphenolic content and minerals. Importantly, the neera filtrate obtained through the optimized nanofibrous membrane showed a 2 log-reduction in yeast load. The effective reusability of the membrane and stability of the nanofiber morphology at repeated usage was confirmed. This approach shows prospects for neera filtration while retaining nutrient content and can be extended to other natural extract applications.
\end{abstract}

\section{Graphic abstract}

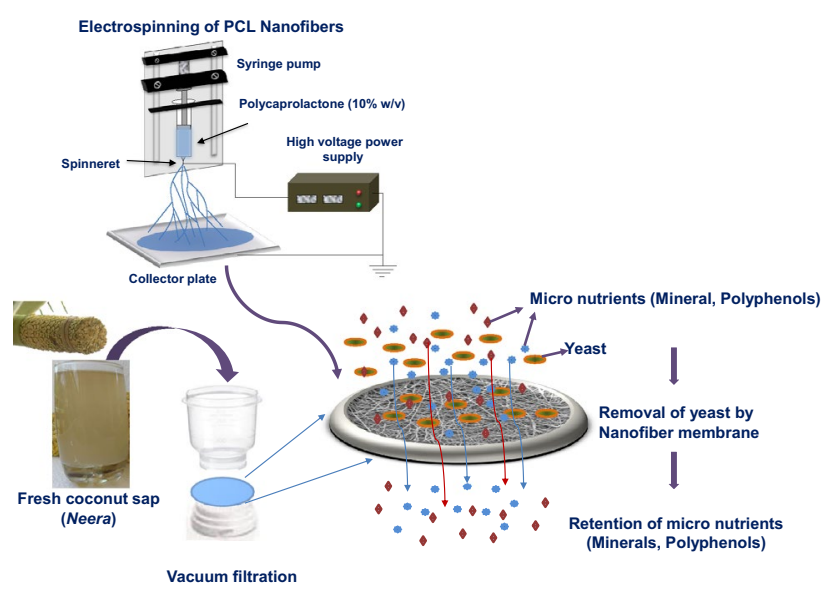

Keywords Coconut neera $\cdot$ Yeasts $\cdot$ Filtration $\cdot$ Electrospinning $\cdot$ Nanofiber membrane

C. Anandharamakrishnan anandharamakrishnan@iifpt.edu.in

1 Computational Modeling and Nanoscale Processing Unit, Indian Institute of Food Processing Technology (IIFPT), Ministry of Food Processing Industries, Government of India, Thanjavur, Tamil Nadu 613 005, India

\section{Introduction}

Coconut sap (neera) from the coconut tree (Cocos nucifera L.) is a healthy and refreshing drink. Fresh neera is sweet, contains sugars with less percentage of fructose, 
oyster-white, and translucent in appearance [1]. It is rich in amino acids, minerals, and vitamins. It has a neutral $\mathrm{pH}$, low calorific value, and low glycemic index (around 35) $[2,3]$. Neera provides various health benefits; for example, it is known to improve digestion, provides instant energy, prevents damage of cells, lowers blood pressure, reduces cholesterol level, contributes to skin health. It also aids in postoperative care due to the presence of high electrolyte contents [4]. This explains the growing demand for this product and necessitates the requirement for appropriate post-harvest processing and preservation techniques. This is of significant interest as coconut as a crop is specific to certain regions of the world, and value addition/preservation of neera has significant health, technological, and economic benefits [5].

Neera is highly susceptible to natural fermentation by the inherent yeasts (particularly Saccharomyces cerevisiae) $[6,7]$. Sugar is a major constituent in neera $(14-18 \%$ w/v) [4] and gets rapidly transformed into alcohol by the fermentation process $[8,9]$. Fermented neera is known as 'toddy', an alcoholic beverage [9, 10]. Alternatively, an acetic fermentation process can yield 'coconut vinegar' $[11,12]$. Post-harvest processing and preservation techniques hold an indispensable role in the shelf-life of coconut neera. Especially, the removal of yeast from coconut neera is a major concern associated with quality. Numerous research works have attempted to do so, using a range of thermal and non-thermal processing methods. However, the problem remains, particularly as the need is to retain the 'fresh-like' attributes of neera [13-15].

Electrospinning is an electrohydrodynamic process that involves the fabrication of nanofibrous membranes by the random orientation of non-woven nanofibers under high electrostatic fields at a voltage of around $1-30 \mathrm{kV}$ $[16,17]$. Electrospun nanofibers have versatile applications in biomedical (scaffolds, drug delivery, regenerative medicine, medical textile, protective masks), textile (smart fabrics, protective clothing, waterproof textiles), environmental protection, food packaging, sensing, immobilization, catalyst, filtration, membranes, and cosmetic sectors [18-22]. Interestingly, nanofibrous membranes have a high surface-area-to-volume ratio which allows permeate flow at a higher rate, and the porosity of the nanofibrous membrane is responsible for filtration efficiency [23]. The applications of the electrospun nanofibrous membrane in food science, beverage, and water filtration/ treatment are well documented [24-27]. Nanofibrous membranes have been explored for different beverage filtration applications ranging from clarification to removal to selective adsorption of unwanted polyphenols [28]. Interestingly, in certain cases, they can offer a 'one-step' clarification process without the need for filter aids and enzymatic treatments in beverage processing.
This work reports the first-of-its-kind study on the filtration of neera using an electrospun nanofibrous membrane. It demonstrates the use of electrospun polycaprolactone (PCL) nanofibrous membrane for coconut neera filtration. The interconnected porosity of nanofibrous membranes does not allow macromolecules (in this case, yeast with an average size of 4-10 $\mu \mathrm{m}$ ) to penetrate through the membrane. However, it can allow micromolecules, micronutrients, and antioxidants, to flow through the membrane. PCL is a lowcost biodegradable synthetic polymer and exhibits good mechanical and antimicrobial properties. It is a biocompatible material approved by the U.S. Food and Drug Administration (FDA) [29, 30]. Also, it is authorized as a direct food contact material by the European Food Safety Authority (EFSA) and FDA [31, 32]. Hence, PCL was chosen as the polymeric material for nanofibrous membrane fabrication. The findings of this study will explicit the ability of electrospun nanofibrous membrane in the removal of yeasts from coconut neera.

\section{Materials and methods}

\section{Chemicals and materials}

PCL (average Mn 80,000), chloroform (anhydrous $\geq 99 \%$ ), ethanol (absolute) were obtained from Sigma Aldrich Chemicals Pvt. Ltd., Bengaluru, India. Methanol, Folin-Ciocalteu's phenol reagent, phenolphthalein indicator $(0.1 \% \mathrm{w} / \mathrm{v})$, sodium hydroxide anhydrous, and chloramphenicol yeast glucose agar were obtained from HiMedia Laboratories Pvt. Ltd., Mumbai, India. Fresh coconut neera was tapped and harvested from the coconut palm trees at Thanjavur, Tamil Nadu, India.

\section{Nanofibrous membrane formation}

The PCL solution $(10 \% \mathrm{w} / \mathrm{v})$ was prepared in a mixture of chloroform and methanol in the ratio of 7:3. It was stirred using a magnetic stirrer until the polymer dissolved properly. PCL nanofibrous membranes were produced using the electrospinning unit reported by Maria Leena et al. [33] (Model VP30C, Royal Enterprises, Chennai, India) equipped with a digitally controlled syringe pump and high voltage power supply (up to $30 \mathrm{kV}$ ). The polymer feed solution was filled in a $5 \mathrm{ml}$ syringe with a stainless steel spinneret needle and was placed perpendicularly over the collector plate with the ground electrode connection. The spinneret needle was connected with the power supply at a high voltage, and a potential difference was created between the spinneret needle and the collector plate. The flow rate of feed solution and the work distance between the spinneret needle and the collector plate were varied at fixed a voltage 
of $15 \mathrm{kV}$ (optimized to form Taylor cone, based on preliminary trials). These nanofibrous membranes were coded as NF01, NF02, and NF03 based on the different experimental conditions (Table 1).

\section{Characterization of nanofibrous membranes}

\section{Morphology analyses}

The nanofibrous membranes were sputter-coated with gold at $10 \mathrm{~mA}$ applied current for $60 \mathrm{~s}$ using a mini magnetron sputtering unit (Model SC7620, Quorum Technologies Ltd., Lewes, UK), and the morphology characteristics of nanofibers were examined using a scanning electron microscopy (SEM) (Model VEGA3, Tescan, Czech Republic, EU). Fiber diameter distribution in different nanofibrous membranes and average diameter of nanofibers was estimated by measuring the diameter of randomly selected 25 fibers from the original SEM micrograph using the IMAGE J software (National Institute of Health, Bethesda, Maryland, USA). The thickness of nanofibrous membranes was measured using a digital micrometer (with $\pm 0.001 \mathrm{~mm}$ accuracy) (3109-25S, Insize India LLP, Gujarat, India).

\section{Porosity}

The porosity of PCL nanofibrous membranes (NF01, NF02, and NF03) was estimated using a pycnometer (Borosil ${ }^{\circledR}$ ) [23]. Based on Archimedes' displacement principle the membrane porosity was calculated using Eq. (1).

Porosity $(\%)=\frac{W_{2}-W_{3}-W_{m}}{\rho_{e}} / \frac{W_{1}-W_{3}}{\rho_{e}} \times 100$

where $W_{1}$ is the weight of ethanol filled pycnometer (in g), $W_{2}$ is the weight of pycnometer filled with absolute ethanol and nanofibrous membrane (in g), $W_{3}$ is the weight of the pycnometer with retained ethanol after removal of

Table 1 Experimental conditions during the electrospinning process for nanofibrous membrane formation

\begin{tabular}{|c|c|c|c|c|c|}
\hline \multirow[t]{2}{*}{ Sample } & \multicolumn{4}{|c|}{ Electrospinning conditions } & \multirow{2}{*}{$\begin{array}{l}\text { Mean thick- } \\
\text { ness of the } \\
\text { nanofibrous } \\
\text { membrane } \\
(\mu \mathrm{m})\end{array}$} \\
\hline & $\begin{array}{l}\text { Distance } \\
\text { between } \\
\text { spinneret } \\
\text { needle } \\
\text { and col- } \\
\text { lector } \\
\text { plate }(\mathrm{cm})\end{array}$ & $\begin{array}{l}\text { Size of } \\
\text { spinneret } \\
\text { needle } \\
\text { (G) }\end{array}$ & $\begin{array}{l}\text { Feed } \\
\text { flow rate } \\
(\mathrm{ml} / \mathrm{h})\end{array}$ & $\begin{array}{l}\text { Applied } \\
\text { voltage } \\
(\mathrm{kV})\end{array}$ & \\
\hline NF01 & 10 & 24 & 2.4 & 15 & \multirow{3}{*}{$\begin{array}{l}\text { Fixed as } \\
\quad \sim 150\end{array}$} \\
\hline NF02 & 8 & 24 & 1.6 & 15 & \\
\hline NF03 & 8 & 24 & 0.8 & 15 & \\
\hline
\end{tabular}

the ethanol-soaked nanofibrous membrane from $W_{2}$ (in g), $W_{m}$ is the dry weight of the nanofibrous membrane (in $\mathrm{g}$ ), and $\rho_{e}$ is the density of ethanol (in $\mathrm{g} / \mathrm{cm}^{3}$ ).

\section{Neera filtration}

Harvested neera was quickly stored under refrigeration temperature after any visual impurity was removed. The filtration process was immediately commenced. The filtration process was performed using a borosilicate glass filtration assembly (Borosil@-5350029) with an oil-free vacuum pump. The filtration assembly consisted of a filtrate flask $(1000 \mathrm{ml})$, funnel $(300 \mathrm{ml})$, anodized aluminum spring clamp, and fritted glass support base ( $47 \mathrm{~mm}$ diameter) with an integral vacuum connection. The filtration base had an effective filtration area of $9.6 \mathrm{~cm}^{2}$. Fabricated PCL nanofibrous membranes (NF01, NF02, and NF03) were cut into a circular shape $($ diameter $=47 \mathrm{~mm})$ and fit in the support base of the filtration unit. Neera was filtered through the nanofibrous membrane under vacuum, and the time taken was recorded. Permeate flow rate across the nanofibrous membrane during filtration was estimated as the time taken for a specified volume of the sample to get filtered. The filtration was performed in a sterile environment, and all glasswares used were previously sterilized in an autoclave at $121^{\circ} \mathrm{C}$ for $15 \mathrm{~min}$ to prevent any contamination.

To access the reusability of the nanofiber membrane after filtration, the membrane was washed with water and $70 \%$ ethanol and dried. Before the next use, it was UV sterilized for $20 \mathrm{~min}$ and reused for filtration of neera using the filtration setup. The repeatability of the membrane was tested multiple times considering changes in flux.

\section{Biochemical characteristics of neera filtrate}

\section{Total soluble solids and titratable acidity}

Total soluble solids (TSS) content of neera samples was determined using a portable handheld digital refractometer (range 0-32\%) (RHB-32ATC, ERMA, Tokyo). In the refractometer, the sample drop was placed on the angled prism and sealed with the clear plate. The readings of total soluble solids were recorded in terms of ${ }^{\circ}$ Brix [34]. Titratable acidity (TA) of neera samples was determined according to the AOAC method. A $25 \mathrm{ml}$ of neera sample was added with two drops of phenolphthalein indicator and titrated with sodium hydroxide $(\mathrm{NaOH})$ solution $(0.1 \mathrm{~N})$ until reaching the endpoint (appearance of permanent pink color). Acidity was measured in terms of the percentage of citric acid using Eq. (2) $[34,35]$. 
Titratable Acidity $(\%)=\frac{V_{\mathrm{NaOH}} \times N_{\mathrm{NaOH}} \times F_{\mathrm{Meq}}}{V_{\text {Sample }}} \times 100$

where $V_{\mathrm{NaOH}}$ is the volume of $\mathrm{NaOH}$ solution used for titration (in $\mathrm{ml}$ ), $N_{\mathrm{NaOH}}$ is the normality of $\mathrm{NaOH}$ solution (in $\left.\mathrm{mol} / \mathrm{m}^{3}\right), F_{\text {Meq }}$ is the milliequivalent factor of citric acid (0.0064), and $V_{\text {Sample }}$ is the volume of the neera sample used for titration (in $\mathrm{ml}$ ).

\section{Color and $\mathrm{pH}$}

CIE color values of the neera samples were determined using a colorimeter (Color Flex ${ }^{\circledR}$ EZ, Hunter Associates Laboratory, Inc., USA). $L^{*}, a^{*}$, and $b^{*}$ values were recorded, and the color change $\left(\Delta E^{*}\right)$ was calculated using Eq. (3).

$\Delta E^{*}=\sqrt{\left(L_{0}^{*}-L^{*}\right)^{2}+\left(a_{0}^{*}-a^{*}\right)^{2}+\left(b_{0}^{*}-b^{*}\right)^{2}}$

where $L_{0} *, a_{0} *$, and $b_{0} *$ are color space values of the fresh neera; $L^{*}, a^{*}$, and $b^{*}$ are color space values of the neera filtrate.

The $\mathrm{pH}$ of the neera samples was determined using a pH meter (PC 700, Eutech Instruments Pte. Ltd.; accuracy $\pm 0.01 \mathrm{pH})$.

\section{Total polyphenol content}

Total polyphenol content (TPC) in the neera filtrate was estimated by the Folin-Ciocalteu method [36] and compared with fresh neera (control). The optical density (OD) of samples was observed at $765 \mathrm{~nm}$ using a multi-mode microplate reader (SpectraMax ${ }^{\circledR}$ iD3, Molecular Devices LLC, USA). TPC of the samples was calculated from a gallic acid standard curve and results were mentioned in terms of gallic acid equivalents (GAE $\mu \mathrm{g} / \mathrm{ml})$.

\section{Estimation of minerals}

Mineral contents present in neera filtrate were determined according to the AOAC method by using inductively coupled plasma optical emission spectrometry (ICP-OES) (Optima ${ }^{\mathrm{TM}}$ 2000 DV, PerkinElmer Inc, Shelton, CT, USA) equipped with WinLab32 ${ }^{\mathrm{TM}}$ software (ver.7.0) [37].

\section{Enumeration of yeasts}

Yeast cell load was determined by the standard spread plate method. A ten-fold serial dilutions of each sample (control, NF01, NF02, and NF03) were made with sterile double distilled water and $50 \mu$ of the sample was spread plated on chloramphenicol yeast glucose agar; the plates were incubated at $25{ }^{\circ} \mathrm{C}$ for $48 \mathrm{~h}$. Enumeration of yeasts was done by following the standard protocol according to IS 5403 method
[38]. Yeast cell count was estimated as colony forming units (CFU) per ml.

\section{Statistical analysis}

All the experiments were carried out in triplicates, and the results were statistically analyzed by one-way ANOVA and interpreted with Duncan's post hoc test $(P<0.05)$ using SPSS (ver. 21.0; IBM, Armonk, NY, USA).

\section{Results and discussion}

\section{Characterization of nanofibrous membranes}

\section{Morphology analysis}

The surface morphology of PCL nanofibrous membranes is shown in Fig. 1. The average diameter of nanofibers was observed to be $1.66 \mu \mathrm{m}, 942 \mathrm{~nm}$, and $857 \mathrm{~nm}$ for NF01, $\mathrm{NF} 02$, and NF03, respectively. The random orientation of fibers having diameters in nanoscale was formed with a decrease in flow rate to $0.8 \mathrm{ml} / \mathrm{hr}$ at $15 \mathrm{kV}$ voltage and $8 \mathrm{~cm}$ distance. The fiber diameter distribution in different nanofibrous membranes confirms that with a decrease in flow rate the fiber diameter decreases and formed uniform fiber size distribution. Lala et al. [39] reported cellulose acetate, polyacrylonitrile (PAN), and poly(N-vinyl chloride) electrospun nanofiber membranes with a nanofiber diameter of $415 \mathrm{~nm}$, $153 \mathrm{~nm}$, and $599 \mathrm{~nm}$, respectively, for usage as filters to protect from bacterial contaminants.

\section{Porosity}

The influence of the electrospinning process parameters on the porosity of nanofiber membranes was investigated. The porosity of the nanofibrous membrane was determined as a fraction of the void in a total volume of the nanofibrous membrane using a pycnometer. The percentage of porosity of nanofibrous membranes was observed to be $76.16 \pm 0.84$, $73.26 \pm 1.62$, and $69.55 \pm 0.86$ for NF01, NF02, and NF03, respectively. Figure $2 \mathrm{a}$ shows the porosity of different nanofibrous membranes. The results expressed that there were significant differences in the porosity among NF01, NF02, and NF03 membranes. In a study by Najafi et al. [40], the polysulfone and polysulfone/Triton X-100 nanofiber membranes with a mean diameter of $1069 \pm 82.84 \mathrm{~nm}$ and $919.2 \pm 66.89 \mathrm{~nm}$, respectively, and porosity of $77.5 \pm 4.5 \%$ and $80.5 \pm 4 \%$, respectively, were tested for the concentration of pomegranate juice. The fiber diameter and porosity values are similar to the result observed in this study. It was observed that with high internal porosity the permeate flux increased in the nanofibrous membrane. 
NF 01

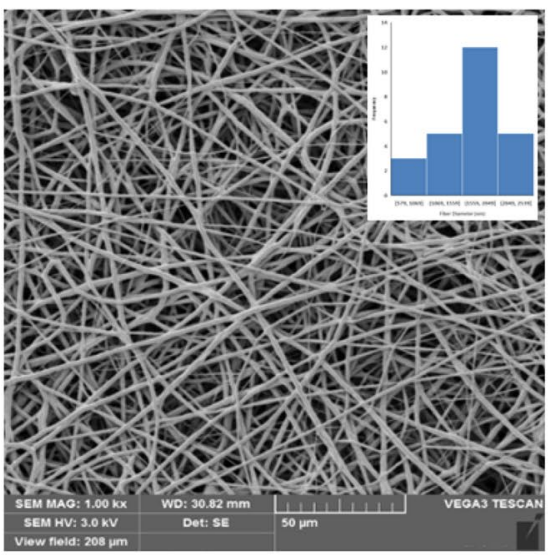

Magnification at $1000 x$

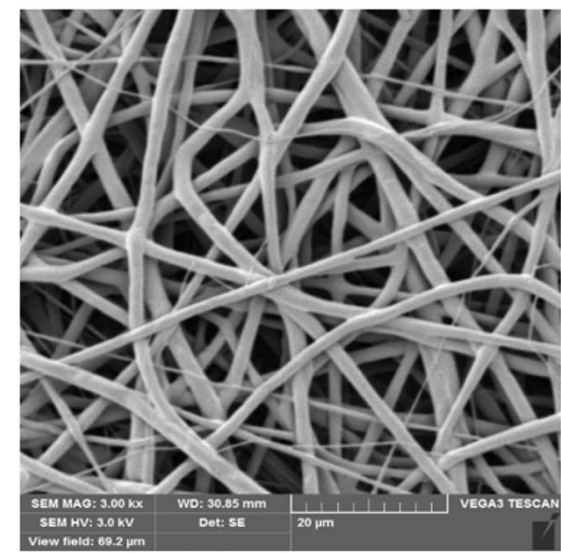

Magnification at 3000x
NF 02

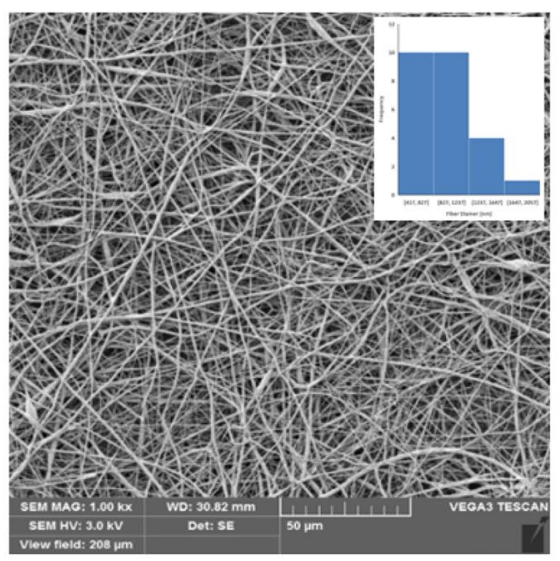

Magnification at $1000 x$

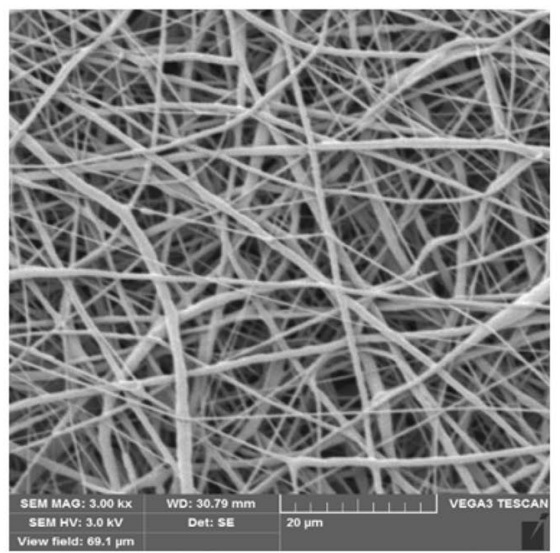

Magnification at $\mathbf{3 0 0 0 x}$
NF 03

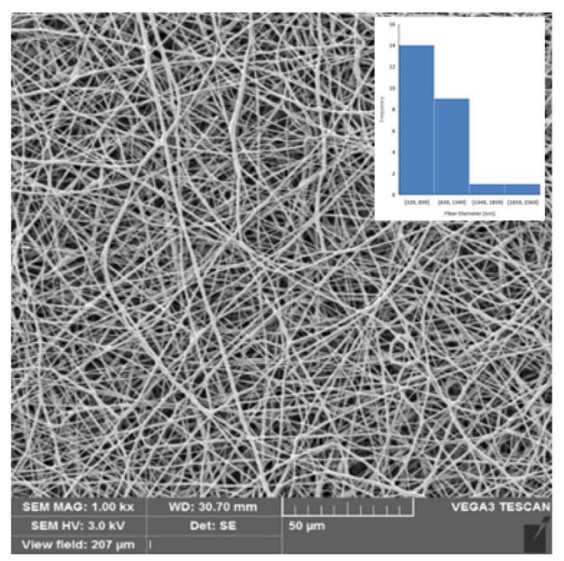

Magnification at $1000 x$

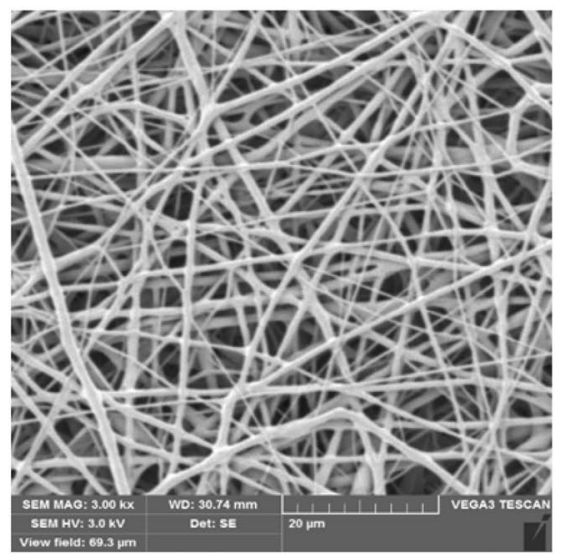

Magnification at $\mathbf{3 0 0 0 x}$

Fig. 1 SEM micrographs of the fabricated nanofibrous membranes

Fig. 2 a Porosity of different nanofibrous membranes and $\mathbf{b}$ Permeate flow rate of neera across the nanofibrous membranes

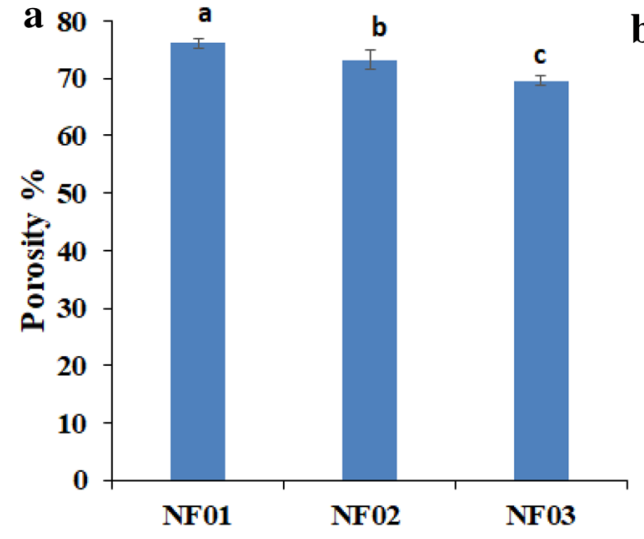

\section{Permeate flow rate during neera filtration}

The permeate flow rate of neera passed through the pores of the nanofibrous membrane was estimated by calculating the time required for the filtration process. The permeate flow rate was found to be $6.73 \pm 0.99 \mathrm{~L} / \mathrm{h}, 6.61 \pm 0.94 \mathrm{~L} / \mathrm{h}$, and $2.94 \pm 0.39 \mathrm{~L} / \mathrm{h}$ for NF01, NF02, and NF03, respectively. Figure $2 \mathrm{~b}$ shows the permeate flow rate of neera across the nanofibrous membranes. The results expressed that there was no significant difference in porosity between NF01 and 
NF02 membranes. But both these membranes showed significant differences from the NF03 membrane. Thus, the results demonstrate that the porosity of the nanofibrous membrane has a great impact on the flow rate of permeate. It was observed that the permeate flow rate was increased with an increase in porosity of the membrane. Thus, the permeability of filtrate depends on the porosity of the nanofibrous membranes. Fuenmayor et al., [41] reported that the high porosity (94\%) of the electrospun nylon-6 nanofibrous membrane was solely responsible for the increase in permeate flux $(1.30 \mathrm{~kg} /$ $\mathrm{m}^{2} \mathrm{~h}$ ) across the membrane. Adsorption of particles or impurities reduces the porosity of the membrane and leads to a decrease in permeate flux across the membrane. The vacuum can be applied on the downstream side of the membrane to increase the permeate flow rate, thereby enhancing the permeate flux of the membrane. Furthermore, this nanofiber membrane showed better retention of antioxidant activity of apple juice, while selectively removing the bitter phenolic compounds. The nanofiber membrane showed superior performance in removal of color and turbidity compared to the microporous membrane and supported extended stability and shelf-life of beverage products. Bortolassi et al. [42] fabricated a PAN-based composite nanofiber filtration membrane using an electrospinning method and reported mean nanofiber diameters of $292 \pm 6 \mathrm{~nm}, 242 \pm 5 \mathrm{~nm}$, and $289 \pm 5 \mathrm{~nm}$ for $\mathrm{Ag} / \mathrm{PAN}, \mathrm{TiO}_{2} / \mathrm{PAN}$, and $\mathrm{ZnO} / \mathrm{PAN}$ nanofibrous membranes, respectively, which formed mean pore sizes of $1.12 \pm 0.10 \mu \mathrm{m}, 1.45 \pm 0.10 \mu \mathrm{m}$, and $2.03 \pm 0.10 \mu \mathrm{m}$, respectively. Also, they observed that $\mathrm{Ag} / \mathrm{PAN}$ electrospun nanofibrous membranes show the highest permeability than other counterparts $\left(\mathrm{TiO}_{2} / \mathrm{PAN}, \mathrm{ZnO} / \mathrm{PAN}\right)$ due to reduced pressure drop (68.13 $\mathrm{Pa})$ across the filter.

\section{Biochemical characteristics of neera filtrate}

Biochemical parameters of the neera filtrate using different nanofibrous membranes and control are listed in Table 2.

\section{Total soluble solids and titratable acidity}

TSS indicates the sugar content of the neera sample and is considered a major quality parameter for neera. It was determined by the index of refraction using a refractometer, and the values were compared with the control. TSS of the samples was measured in terms of ${ }^{\circ} \mathrm{Brix}$, and it was observed to be $16.70 \pm 0.17,16.47 \pm 0.47,15.60 \pm 0.72$, and $15.07 \pm 1.80$ for control, NF01, NF02, and NF03, respectively. The results showed that the neera filtrate had slightly lower TSS as compared to the neera control. However, there were no significant differences in TSS content among the neera filtrates filtered across the different nanofibrous membranes as well as with the control. Cassano et al. [43] developed poly(ether ether ketone) and polysulfone membranes by the dry-wet spinning method for pomegranate juice clarification reported that the TSS content ( $\left({ }^{\circ} \mathrm{Brix}\right)$ of juice was reduced to $15.4 \pm 0.25$ and $15.4 \pm 0.09$ from $16.0 \pm 0.10$ and $16.0 \pm 0.28$ while filtration through the poly(ether ether ketone) and polysulfone membranes, respectively. In a different study, Lemma et al. [44] reported the TSS content of beer $\left(5.33 \pm 0.05^{\circ} \mathrm{Brix}\right)$ remained constant even after filtration with the electrospun nylon nanofibrous membrane. Najafi et al. [40] used a nanofiber membrane to concentrate the pomegranate juice and reported that the TSS content of $35.7^{\circ} \mathrm{Brix}$ was arrived after concentrated with polysulfone/Triton X-100 nanofiber membrane. Battirola et al. [45] observed a significant reduction in TSS contents in fruit juices and whey after filtration with the cellulose acetate/cellulose nanofiber membranes. They reported that the TSS content $\left({ }^{\circ} \mathrm{Brix}\right)$ of strawberry and raspberry juices were reduced to $1.95 \pm 0.49$ and $2.55 \pm 0.07$ from $2.95 \pm 0.07$ and $2.90 \pm 0.00$, respectively. Similarly, the TSS content $\left({ }^{\circ}\right.$ Brix) of whey was reduced to $6.88 \pm 0.85$ and $6.10 \pm 0.00$ from $7.40 \pm 0.14$ and $6.35 \pm 0.07$ while filtration through the cellulose acetate/cellulose nanofiber membrane in the dead-end cell and tangential modules, respectively.

Table 2 Biochemical and physical parameters of the neera filtrate and the fresh neera (control)

\begin{tabular}{|c|c|c|c|c|c|c|c|c|c|}
\hline \multirow[t]{2}{*}{ Sample } & \multirow[t]{2}{*}{ TSS $\left({ }^{\circ}\right.$ Brix $)$} & \multirow{2}{*}{$\begin{array}{l}\text { TA (\% of } \\
\text { citric acid) }\end{array}$} & \multirow[t]{2}{*}{$\mathrm{pH}$} & \multicolumn{3}{|c|}{ CIE color values } & \multirow{2}{*}{$\begin{array}{l}\text { Color differ- } \\
\text { ence }\left(\Delta E^{*}\right)\end{array}$} & \multirow{2}{*}{$\begin{array}{l}\text { TPC (GAE } \mu \mathrm{g} / \\
\mathrm{ml})\end{array}$} & \multirow{2}{*}{$\begin{array}{l}\text { Yeast load } \\
(\mathrm{CFU} / \mathrm{ml})\end{array}$} \\
\hline & & & & $L^{*}$ & $a^{*}$ & $b^{*}$ & & & \\
\hline Control & $16.70 \pm 0.17^{\mathrm{a}}$ & $2.77 \pm 0.20^{\mathrm{a}}$ & $6.13 \pm 0.21^{\mathrm{a}}$ & $9.73 \pm 0.12^{\mathrm{a}}$ & $-0.57 \pm 0.08^{\mathrm{a}}$ & $-2.02 \pm 0.02^{\mathrm{a}}$ & - & $128.42 \pm 1.65^{\mathrm{a}}$ & $1.55 \times 10^{6}$ \\
\hline NF01 & $16.47 \pm 0.47^{\mathrm{a}}$ & $1.98 \pm 0.29^{b}$ & $6.67 \pm 0.01^{\mathrm{b}}$ & $3.56 \pm 0.06^{\mathrm{b}}$ & $-0.32 \pm 0.05^{\mathrm{b}}$ & $-1.19 \pm 0.04^{\mathrm{b}}$ & $6.22 \pm 0.07^{\mathrm{a}}$ & $128.05 \pm 2.35^{\mathrm{a}}$ & $1.07 \times 10^{5}$ \\
\hline NF02 & $15.60 \pm 0.72^{\mathrm{a}}$ & $1.88 \pm 0.15^{\mathrm{b}}$ & $6.74 \pm 0.08^{b}$ & $3.34 \pm 0.06^{\mathrm{c}}$ & $-0.29 \pm 0.05^{\mathrm{b}}$ & $-1.20 \pm 0.13^{\mathrm{b}}$ & $6.45 \pm 0.15^{\mathrm{b}}$ & $123.51 \pm 2.24^{\mathrm{b}}$ & $2.57 \times 10^{4}$ \\
\hline NF03 & $15.07 \pm 1.80^{\mathrm{a}}$ & $1.77 \pm 0.04^{\mathrm{b}}$ & $6.78 \pm 0.10^{\mathrm{b}}$ & $3.28 \pm 0.01^{\mathrm{c}}$ & $-0.27 \pm 0.06^{\mathrm{b}}$ & $-1.21 \pm 0.03^{b}$ & $6.51 \pm 0.11^{\mathrm{b}}$ & $123.42 \pm 0.59^{b}$ & $2.38 \times 10^{4}$ \\
\hline
\end{tabular}

Results were expressed as mean \pm SD $(n=3)$; different superscripts of lowercase letters along the samples in each parameter represent significant differences at $P<0.05$ level 
TA indicates the acidity of the neera samples. The acidity of the neera filtrate and fresh neera (control) was measured in terms of the percentage of citric acid. The percentage of TA was found to be $2.77 \pm 0.20,1.98 \pm 0.29,1.88 \pm 0.15$, and $1.77 \pm 0.04$ for control, NF01, NF02, and NF03, respectively. The results showed that the nanofiber filtration process efficiently decreased the TA of neera. There was no significant difference in TA among the neera filtrates, but the filtrates showed a significant difference against the control.

\section{Color and $\mathrm{pH}$}

Color and $\mathrm{pH}$ are crucial quality indicators, particularly for liquid foods/beverages. In this case, the color values reveal the clarity of neera filtrate. $L^{*}$ values were found to be $9.73 \pm 0.12,3.56 \pm 0.06,3.34 \pm 0.06$, and $3.28 \pm 0.01$ for control, NF01, NF02, and NF03, respectively. The results showed that the $L^{*}$ values were significantly lower in the neera filtrates as compared with the fresh neera control. This also explains the turbidity reduction in the neera filtrates. NF03 showed a lower $L^{*}$ value followed by NF02 and NF01. There was no significant difference in lightness between NF02 and NF03 neera filtrates, both these samples showed significant differences in lightness with NF01 neera filtrate. Neera filtrates exhibited higher $a^{*}$ and $b^{*}$ values. $\Delta E^{*}$ values were found to be $6.22 \pm 0.07,6.45 \pm 0.15$, and $6.51 \pm 0.11$ for NF01, NF02, and NF03, respectively. Higher $\Delta E^{*}$ of the neera filtrates from NF02 and NF03 indicates the high clarity of the neera filtrate. There was no significant color difference between NF02 and NF03 neera filtrates, both these samples showed significant color differences with NF01 neera filtrate.

The $\mathrm{pH}$ of the neera filtrates was slightly higher than the $\mathrm{pH}$ of the fresh neera control, indicating that the neera filtrate had low acidity as compared with the fresh neera (Table 2). NF03 showed lower acidity followed by NF02 and NF01. But there were no significant differences among the neera filtrates. Fuenmayor et al. [41] reported that the $\mathrm{pH}$ of the apple juice $(3.4 \pm 0.1)$ remained constant after filtration with an electrospun nylon-6 nanofibrous membrane. Similarly, Lemma et al. [44] reported that the $\mathrm{pH}$ of beer $(4.3 \pm 0.1)$ remained constant after filtration with the electrospun nylon nanofibrous membrane. Battirola et al. [45] reported that no significant differences in the $\mathrm{pH}$ of strawberry juice (3.53), raspberry juice (3.33), and whey (4.47) after filtration with a cellulose acetate/cellulose nanofiber membrane.

\section{Total polyphenol content}

The fresh neera exhibited a higher TPC, whereas neera filtrates showed slight reductions. TPC was measured in terms of GAE $(\mu \mathrm{g} / \mathrm{ml})$ and was found to be $128.42 \pm 1.65$, $128.05 \pm 2.35,123.51 \pm 2.24$, and $123.42 \pm 0.59$ for control, NF01, NF02, and NF03, respectively. The NF01 neera filtrate showed no significant difference with the fresh neera (control). Similarly, there was no significant difference between NF02 and NF03 neera filtrates. But NF02 and NF03 neera filtrates showed significant differences with NF01 neera filtrate and the fresh neera control. Cassano et al. [43] reported that the TPC of pomegranate juice (hesperidin equivalent $\mathrm{g} / \mathrm{L}$ ) was reduced to $1.062 \pm 0.02$ and $1.177 \pm 0.02$ from $1.576 \pm 0.03$ and $1.571 \pm 0.03$ when filtered through poly(ether ether ketone) and polysulfone membranes, respectively. Fuenmayor et al. [41] observed a significant reduction in the TPC of apple juice after filtration with a nylon- 6 nanofibrous membrane and reported a reduction of TPC from $327 \pm 3$ to $83 \pm 3$ (ppm gallic acid).

\section{Estimation of minerals}

The presence of key minerals highlights the nutritional value of coconut neera. Mineral contents such as calcium, magnesium, zinc, sodium, phosphorous, potassium, copper, and manganese were quantified using ICP-OES (Table 3). A
Table 3 List of minerals identified by ICP-OES in the neera filtrate (NF02) and the fresh neera (control)

\begin{tabular}{lllll}
\hline Minerals & Neera control $(\mu \mathrm{g} / \mathrm{ml})$ & Neera filtrate $(\mu \mathrm{g} / \mathrm{ml})$ & $\begin{array}{l}\text { Difference between con- } \\
\text { trol and filtrate }(\mu \mathrm{g} / \mathrm{ml})\end{array}$ & \% Reduction \\
\hline $\mathrm{Cu}$ & $0.013 \pm 0.000^{\mathrm{a}}$ & $0.010 \pm 0.001^{\mathrm{b}}$ & $0.003 \pm 0.001$ & 23.08 \\
$\mathrm{Mn}$ & $0.005 \pm 0.001^{\mathrm{a}}$ & $0.003 \pm 0.001^{\mathrm{b}}$ & $0.002 \pm 0.000$ & 44.44 \\
$\mathrm{Mg}$ & $0.825 \pm 0.031^{\mathrm{a}}$ & $0.732 \pm 0.030^{\mathrm{b}}$ & $0.093 \pm 0.001$ & 11.27 \\
$\mathrm{Zn}$ & $0.179 \pm 0.007^{\mathrm{a}}$ & $0.176 \pm 0.002^{\mathrm{a}}$ & $0.003 \pm 0.009$ & 1.68 \\
$\mathrm{Na}$ & $5.301 \pm 0.651^{\mathrm{a}}$ & $3.690 \pm 0.112^{\mathrm{b}}$ & $1.611 \pm 0.763$ & 30.39 \\
$\mathrm{Ca}$ & $4.344 \pm 0.052^{\mathrm{a}}$ & $4.066 \pm 0.062^{\mathrm{b}}$ & $0.279 \pm 0.010$ & 6.41 \\
$\mathrm{~K}$ & $20.65 \pm 0.660^{\mathrm{a}}$ & $18.675 \pm 0.045^{\mathrm{b}}$ & $1.975 \pm 0.705$ & 9.56 \\
$\mathrm{P}$ & $1.158 \pm 0.034^{\mathrm{a}}$ & $1.022 \pm 0.013^{\mathrm{b}}$ & $0.136 \pm 0.021$ & 11.71 \\
\hline
\end{tabular}

Results were expressed as mean $\pm \mathrm{SD}(\mathrm{n}=3)$; different superscripts of lowercase letters along the mineral content (before and after filtration) represent significant differences at $P<0.05$ level 

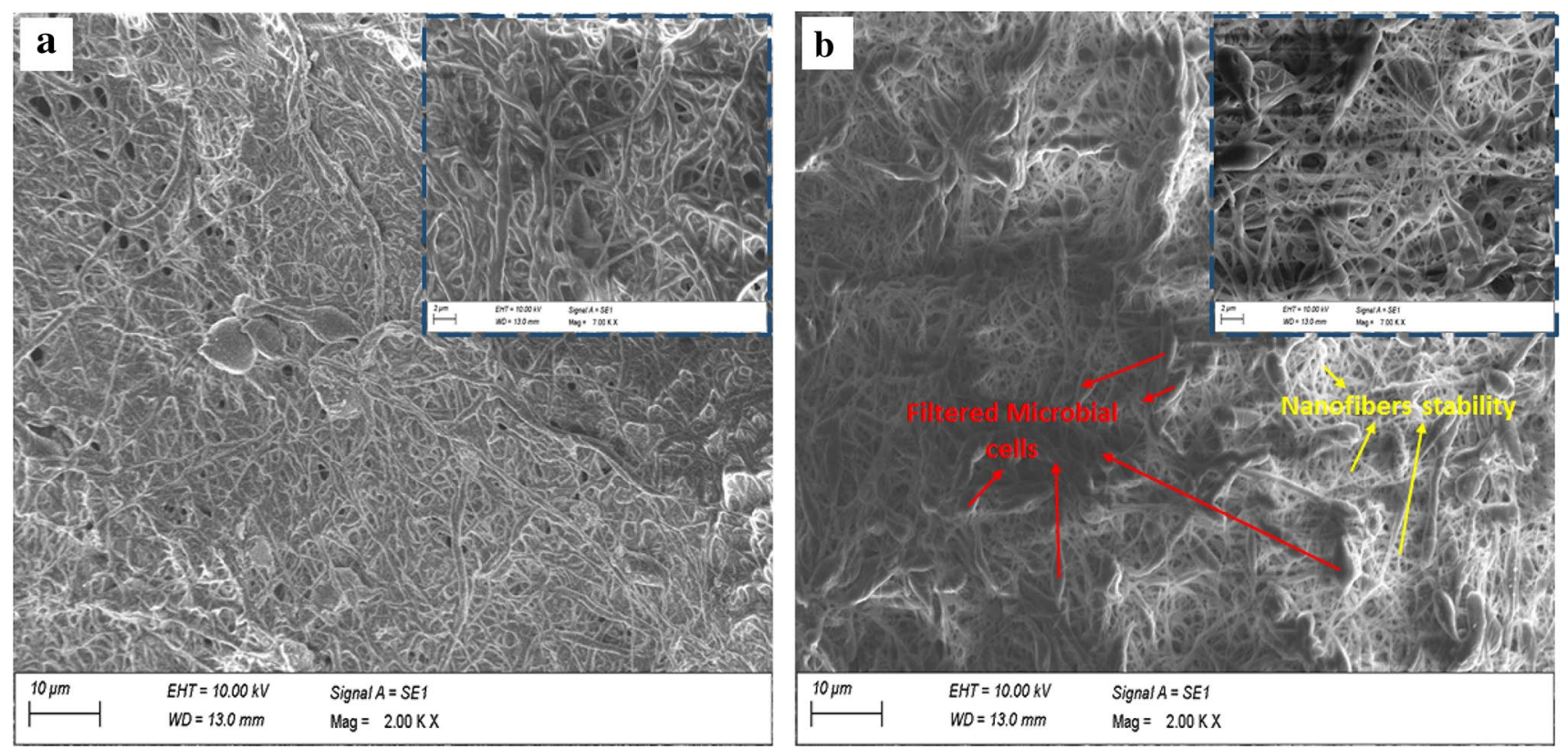

Fig. 3 Nanofiber membrane after the 5th usage a just after the filtration and $\mathbf{b}$ after wash with $70 \%$ ethanol (figure inserts at higher (7000x) magnification)

minimal reduction in mineral contents was observed after nanofiber filtration. The retention of mineral content is an advantage of the nanomembrane filtration process.

\section{Enumeration of yeasts}

Yeast cell load in the neera filtrate and the fresh neera (control) was estimated to be $1.55 \times 10^{6} \mathrm{CFU} / \mathrm{ml}, 1.07 \times 10^{5} \mathrm{CFU} /$ $\mathrm{ml}, 2.57 \times 10^{4} \mathrm{CFU} / \mathrm{ml}$, and $2.38 \times 10^{4} \mathrm{CFU} / \mathrm{ml}$ for control, NF01, NF02, and NF03, respectively. NF03 nanofibrous membrane showed very low yeast load followed by NF02 and NF01. The yeast cell viability showed significant differences between control and neera filtrates. Moreover, NF01 showed significant differences between NF02 and NF03 counterparts. But there was no significant difference between NF02 and NF03. A similar study was reported by Lemma et al. [44], who developed electrospun nylon nanofibrous membranes with a fiber diameter of $197 \pm 31 \mathrm{~nm}$ and porosity of $\sim 90 \%$ and investigated their potential for the removal of bacterial and yeast strains in water and beer. They fortified beer suspensions at different microbial concentrations such as $5.1 \times 10^{8} \mathrm{CFU} / \mathrm{mL}$ of Flavobacterium johnsoniae, $1.0 \times 10^{4} \mathrm{CFU} / \mathrm{mL}$ of Iodobacter fluviatilis, $8.0 \times 10^{8} \mathrm{CFU} /$ $\mathrm{mL}$ of the mixed cultures ( $F$. johnsoniae and I. fluviatilis), and $2.9 \times 10^{8} \mathrm{CFU} / \mathrm{mL}$ of $S$. cerevisiae, and studied the filtration efficiency in removal of these microbial strains. They reported that nylon nanofibrous membranes completely removed yeast ( $S$. cerevisiae) and mixed bacterial cultures ( $F$. johnsoniae and I. fluviatilis); whereas, 3 and 5 $\log$ reductions could be achieved in the beer suspensions fortified with I. fluviatilis and F. johnsoniae, respectively. Bortolassi et al. [42] observed the efficient removal of bacterial cells using the composite-based Ag/PAN nanofiber filtration membrane and reported the reduction of the bacterial load from $10^{8} \mathrm{CFU} / \mathrm{mL}$ to $10^{3} \mathrm{CFU} / \mathrm{mL}$ while filtration through the Ag/PAN nanofibrous membrane. In another study, Ma et al. [46] developed functionalized PAN electrospun membranes by a surface modification process for the removal of bacteria and viruses. They reported that surface-modified PAN electrospun membrane showed efficient removal of Escherichia coli and MS2 phage at $99.9999 \%$ and $99.99 \%$, respectively.

The reusability of the selected nanofiber membrane (NF02) was tested multiple times. At the 5th use, the permeate flow rate was reduced by around $50 \%$. Hence, the yeast count was tested after the 5 th usage, and it found that control levels were the same as at the first usage of the membrane. The morphology of the nanofiber membrane just after the 5th usage of filtration (Fig. 3a) shows the deposition of neera on the membrane. However, after the washing step, fouling on the membrane was removed, and only yeast cells were retained on the membrane (Fig. 3b). It was evident that the nanofiber membrane was stable even after repeated usage, washing, and sterilization processes. This proves the reusability of the prepared membrane and the stability of nanofibers. Comparing the different sterilization techniques for PCL nanofiber membranes, Horakova et al., (2020) proved that soaking in aqueous 
ethanol (70\%) for $30 \mathrm{~min}$ and UV irradiation for $30 \mathrm{~min}$ does not cause any morphological change [48]. This supports the suitability of the selected sterilization technique for the filtration process and reusability of the membrane.

Moreover, with recent advances in the electrospinning technique, large-scale production of nanofibrous membranes is possible [49]. For example, techniques like needleless electrospinning have been proven to be suitable for the mass production of macroscopically homogeneous nanofibrous membranes [48]. Outstanding production capacities of up to $13.7 \mathrm{~g} / \mathrm{h}$ have been achieved with high curvature using needleless electrospinning [50]. Such advancements in manufacturing techniques allow cost-effective usage of such nanomembranes for filtration applications.

\section{Conclusion}

Electrospun nanofibrous membranes were developed using the electrospinning process and used for the filtration of coconut neera. The filtration efficiency of nanofibrous membranes (NF01, NF02, and NF03) fabricated under different process conditions was investigated. The NF03 nanofibrous membrane had very fine pores because of the less nanofiber diameter $(857 \mathrm{~nm})$ and showed low counts of yeast $\left(2.38 \times 10^{4} \mathrm{CFU} / \mathrm{ml}\right)$. But in terms of filtration efficiency, it showed a low permeate flow rate $(2.94 \pm 0.39 \mathrm{~L} / \mathrm{h})$ due to less porosity (69.55\%). The NF02 nanofibrous membrane was optimized because of increased porosity $(73.26 \%)$ and permeate flow rate $(6.61 \pm 0.94 \mathrm{~L} / \mathrm{h})$ while supporting yeast load reduction $\left(2.57 \times 10^{4} \mathrm{CFU} / \mathrm{ml}\right)$. Also, it could retain the TPC and showed TSS, TA, pH, and color equivalent to NF03. Hence, the process parameters involved in the fabrication of NF02 membrane are considered as optimized electrospinning parameters. Further, the NF02 nanofibrous membrane showed better retention of minerals and the efficient removal of yeast cells ( $2 \log$ reduction). Moreover, effective reusability of the nanofibrous membrane was observed for up to 5 usages. Thus, the study confirms the potential of the electrospun nanofibrous membrane for neera filtration, quality retention, and shelf-life extension applications.

Authors' contributions M. Maria leena, K.S. Yoha data curation, data analysis, writing —original draft; J.A. Moses supervision, writingreview and editing; C. Anandharamakrishnan conceptualization, supervision, project administration, writing — review and editing.

Funding Not applicable.

Availability of data and materials Not applicable.

Code availability Not applicable.

\section{Declarations}

Conflict of interest The authors declare no conflicts of interest.

\section{References}

1. Murugesan P, Moses JA, Anandharamakrishnan C (2020) One step synthesis of fluorescent carbon dots from neera for the detection of silver ions. Spectrosc Lett 53:407-415. https://doi.org/10. 1080/00387010.2020.1764589

2. Asghar MT, Yusof YA, Mokhtar MN et al (2020) Processing of coconut sap into sugar syrup using rotary evaporation, microwave, and open-heat evaporation techniques. J Sci Food Agric 100:4012-4019. https://doi.org/10.1002/jsfa.10446

3. Mammen R, John F, Krishnakumar IM et al (2020) Safety and influence of a novel powder form of coconut inflorescence sap on glycemic index and lipid profile. Bioact Carbohydrates Diet Fibre 23:100217. https://doi.org/10.1016/j.bcdf.2020.100217

4. Akkarakaran BA (2015) The health benefits of Neera; value addition potential

5. CDB (2015) Coconut Development Board to market neera as health drink

6. Widyaningrum T, Suharjono, Ardyati T, Aulanni' am (2019) Screening and identification indigenous yeast from neera Siwalan for bioethanol production. In: IOP conference series: earth and environmental science, p 12073

7. Ramalakshmi K, Ramesh M, Raghavan B, Prakash V (2004) Process for the preservation of coconut sap (neera). U.S. Patent Application No. 10/396710

8. Limtong S, Am-In S, Kaewwichian R et al (2020) Exploration of yeast communities in fresh coconut, palmyra, and nipa palm saps and ethanol-fermenting ability of isolated yeasts. Antonie Van Leeuwenhoek 113:2077-2095. https://doi.org/10.1007/ s10482-020-01479-2

9. Pandiselvam R, Hebbar KB, Manikantan MR et al (2020) Microwave treatment of coconut inflorescence sap (Kalparasa $\left.{ }^{\circledR}\right)$ : ssutes. Sugar Tech 22:718-726. https://doi.org/10.1007/ s12355-020-00828-9

10. Singh U, Singh S, Kamal SK (2020) Ethnic fermented foods and beverages of Bihar and Jharkhand. In: Ethnic fermented foods and beverages of India: science history and culture. Springer, pp $105-120$

11. Ghosh D (2015) Postharvest, product diversification and value addition in coconut. In: Value addition of horticultural crops: recent trends and future directions. Springer, New Delhi, pp $125-165$

12. Borse BB, Rao LJM, Ramalakshmi K, Raghavan B (2007) Chemical composition of volatiles from coconut sap (neera) and effect of processing. Food Chem 101:877-880

13. Alagirisamy D (2019) The problem with neera: the (un)making of a national drink in late colonial India. Indian Econ Soc Hist Rev 56:77-97. https://doi.org/10.1177/0019464618816828

14. Hebbar KB, Pandiselvam R, Manikantan MR et al (2018) Palm Sap-quality profiles, fermentation chemistry, and preservation methods. Sugar Tech 1-14

15. Chinnamma M, Bhasker S, Binitha Hari M et al (2019) Coconut neera-a vital health beverage from coconut palms: harvesting, processing and quality analysis. Beverages 5:22

16. Anukiruthika T, Moses JA, Anandharamakrishnan C (2020) Electrohydrodynamic drying of foods: principle, applications, and prospects. J Food Eng 295:110449

17. Leena M, Yoha KS, Moses JA, Anandharamakrishnan C (2019) Electrospraying and spinning techniques: fabrication 
and its potential applications. In: Parthasarathi S, Anandharamakrishnan C (eds) Food nanotechnology: principles and applications. CRC Press, Boca Raton, pp 187-216

18. Xue J, Wu T, Dai Y, Xia Y (2019) Electrospinning and electrospun nanofibers: methods, materials, and applications. Chem Rev 119:5298-5415. https://doi.org/10.1021/acs.chemrev.8b005 93

19. Falco A, Mallavia R (2020) Electrospun nanomaterials: applications in food, environmental remediation, and bioengineering

20. Maria Leena M, Yoha KS, Moses JA, Anandharamakrishnan C (2020) Nanofibers in food applications. In: innovative food processing technologies: a comprehensive review. Reference module in food science. Elsevier

21. Bhushani JA, Anandharamakrishnan C (2014) Electrospinning and electrospraying techniques: potential food based applications. Trends Food Sci Technol 38:21-33. https://doi.org/10.1016/j.tifs. 2014.03.004

22. Jayan H, Maria Leena M, Sivakama Sundari SK et al (2019) Improvement of bioavailability for resveratrol through encapsulation in zein using electrospraying technique. J Funct Foods 57:417-424. https://doi.org/10.1016/J.JFF.2019.04.007

23. Yew CHT, Azari P, Choi JR et al (2018) Electrospun polycaprolactone nanofibers as a reaction membrane for lateral flow assay. Polymers (Basel) 10:1387

24. Veleirinho B, Lopes-da-Silva JA (2009) Application of electrospun poly(ethylene terephthalate) nanofiber mat to apple juice clarification. Process Biochem 44:353-356

25. Chu L, Kang X, Wang Y (2017) Extraction of onion (Allium cepa) essential oil by polystyrene nanofibrous membranes. J Food Process Eng 40:e12318

26. Martins AJ, Bourbon AI, Vicente AA et al (2015) Physical and mass transfer properties of electrospun $\varepsilon$-polycaprolactone nanofiber membranes. Process Biochem 50:885-892

27. Chen H, Huang M, Liu Y et al (2020) Functionalized electrospun nanofiber membranes for water treatment: a review. Sci Total Environ 739:139944

28. Leena MM, Bharathi SKV, Moses JA, Anandharamakrishnan C (2020) Potential applications of nanofibers in beverage industry. In: Nanoengineering in the beverage industry. Elsevier, pp 333-368

29. Dong X, Zhang J, Pang L et al (2019) An anisotropic three-dimensional electrospun micro/nanofibrous hybrid PLA/PCL scaffold. RSC Adv 9:9838-9844

30. Figueira DR, Miguel SP, de Sá KD, Correia IJ (2016) Production and characterization of polycaprolactone-hyaluronic acid/ chitosan-zein electrospun bilayer nanofibrous membrane for tissue regeneration. Int J Biol Macromol 93:1100-1110

31. Mellinas C, Ramos M, Grau-Atienza A et al (2020) Biodegradable poly ( $\varepsilon$-caprolactone) active films loaded with MSU-X mesoporous silica for the release of $\alpha$-tocopherol. Polymers (Basel) 12:137

32. Rijk R, Veraart R (2010) Global legislation for food packaging materials. Wiley, New York

33. Leena MM, Yoha KS, Moses JA, Anandharamakrishnan C (2020) Edible coating with resveratrol loaded electrospun zein nanofibers with enhanced bioaccessibility. Food Biosci 36:100669. https:// doi.org/10.1016/j.fbio.2020.100669

34. Hossain M, Rana M, Kimura Y, Roslan HA (2014) Changes in biochemical characteristics and activities of ripening associated enzymes in mango fruit during the storage at different temperatures. Biomed Res Int 2014:232969
35. AOAC (2000) Official method of analysis of AOAC international, 17 th edn.

36. Passafiume R, Perrone A, Sortino G et al (2019) Chemical-physical characteristics, polyphenolic content and total antioxidant activity of three Italian-grown pomegranate cultivars. NFS J 16:9-14

37. Souza SO, Costa SSL, Brum BCT et al (2019) Determination of nutrients in sugarcane juice using slurry sampling and detection by ICP OES. Food Chem 273:57-63

38. Standard I (1999) Method for yeast and mould count of foodstuffs and animal feeds. Bur Indian Stand Manak Bhawan India 1:1-3

39. Lala NL, Ramaseshan R, Bojun L et al (2007) Fabrication of nanofibers with antimicrobial functionality used as filters: protection against bacterial contaminants. Biotechnol Bioeng 97:1357-1365

40. Najafi A, Emam-Djomeh Z, Askari G, Fathi M (2020) Electrospun hydrophobe nanofibrous membrane based on polysulfone/Triton $\mathrm{x}-100$ : a novel vehicle to concentrate pomegranate juice. J Food Process Eng. https://doi.org/10.1111/jfpe.13493

41. Fuenmayor CA, Mengistu S, Mannino S et al (2014) Filtration of apple juice by nylon nanofibrous membranes. J Food Eng 122:110-116. https://doi.org/10.1016/j.jfoodeng.2013.08.038

42. Bortolassi ACC, Guerra VG, Aguiar ML et al (2019) Composites based on nanoparticle and pan electrospun nanofiber membranes for air filtration and bacterial removal. Nanomaterials. https://doi. org/10.3390/nano9121740

43. Cassano A, Conidi C, Tasselli F (2015) Clarification of pomegranate juice (Punica granatum L.) by hollow fibre membranes: analyses of membrane fouling and performance. J Chem Technol Biotechnol 90:859-866. https://doi.org/10.1002/jctb.4381

44. Lemma SM, Esposito A, Mason M et al (2015) Removal of bacteria and yeast in water and beer by nylon nanofibrous membranes. J Food Eng 157:1-6. https://doi.org/10.1016/j.jfoodeng.2015.02. 005

45. Battirola LC, Andrade PF, Marson GV et al (2017) Cellulose acetate/cellulose nanofiber membranes for whey and fruit juice microfiltration. Cellulose 24:5593-5604. https://doi.org/10.1007/ s10570-017-1510-8

46. Ma H, Hsiao BS, Chu B (2014) Functionalized electrospun nanofibrous microfiltration membranes for removal of bacteria and viruses. J Memb Sci 452:446-452. https://doi.org/10.1016/j. memsci.2013.10.047

47. Azizo AS, Wirzal MDH, Bilad MR, Yusoff ARM (2017) Assessment of nylon 6, 6 nanofibre membrane for microalgae harvesting. AIP Conf Proc. https://doi.org/10.1063/1.5005365

48. Horakova J, Klicova M, Erben J et al (2020) Impact of various sterilization and disinfection techniques on electrospun poly- $\epsilon$ caprolactone. ACS Omega 5:8885-8892. https://doi.org/10.1021/ acsomega.0c00503

49. Persano L, Camposeo A, Tekmen C, Pisignano D (2013) Industrial upscaling of electrospinning and applications of polymer nanofibers: a review. Macromol Mater Eng 298:504-520. https://doi.org/ 10.1002/mame.201200290

50. Xiong J, Liu Y, Li A et al (2021) Mass production of high-quality nanofibers via constructing pre-Taylor cones with high curvature on needleless electrospinning. Mater Des 197:109247. https://doi. org/10.1016/j.matdes.2020.109247

Publisher's Note Springer Nature remains neutral with regard to jurisdictional claims in published maps and institutional affiliations. 